\title{
Comparison of Morphological Profiles and Performance Variables Between Female Volleyball Players of the First and Second Division In Portugal
}

\author{
by \\ Alberto Carvalho ${ }^{1,2,3}$, Paulo Roriz $z^{1,2,3,4,5}$, Daniel Duarte ${ }^{1,2,3}$
}

\begin{abstract}
Knowledge of players' anthropometric profiles may contribute to a better understanding of the differences between their performance levels. For example, vertical jump height, which is a major indicator of a volleyball player's performance, is influenced by favorable anthropometric variables. This study's aim was to describe anthropometric profiles of elite female volleyball players competing in the $1^{\text {st }}$ and $2^{\text {nd }}$ divisions in Portugal and to link these profiles with performance skills such as jump height obtained during blocking and spiking actions. Fifty-nine volleyball players were analyzed according to their competitive level, forming three independent groups: $G A$ ( $n=20, A 1$ division, ranked first), GB ( $n=21$, A1 division, ranked last) and GC ( $n=18$, A2 division). Anthropometric data collected included body mass and height, arm span, seven skinfolds (triceps, biceps, subscapular, suprailiac, abdominal, thigh and calf), four body perimeters (relaxed brachial, contracted brachial, thigh and calf), and two body diameters (humeral and femoral). Performance data included the height obtained during block and spike actions. Significant differences were found between groups (GA/GB from A1 and GC from A2). Players in the GA had the highest body mass (68.05 $\pm 6.62 \mathrm{~kg}, p<$ $0.05)$, body height (176.35 $\pm 6.21 \mathrm{~cm}, p<0.05)$, arm span (177.59 $\pm 6.09 \mathrm{~cm}, p<0.05)$, lean mass $(53.51 \pm 4.94 \mathrm{~kg}, p<$ 0.05 ) and vertical jump heights (block: $0.36 \pm 0.06 \mathrm{~m}$ and spike: $0.43 \pm 0.05 \mathrm{~m}, p<0.05$ ). As expected, the fat mass percentage of $G A$ players was the lowest $(21.30 \pm 2.61 \%)$. The results suggest that anthropometric profiles of volleyball players may vary according to the competitive level. The higher body mass, body height, arm span, and lean mass presented by GA players in comparison with GC players suggest these variables are important for top-level performance, since these athletes also exhibited higher jump heights. Variables such as height and arm span have a considerable genetic influence and could be important for early talent identification in volleyball. Other variables such as body mass, lean mass and vertical jump performance are more complex, since they also reflect the effects of environmental and training conditions.
\end{abstract}

Key words: anthropometric characteristics, volleyball, somatotype, vertical jump.

\section{Introduction}

Volleyball is one of the most popular sports in the world, played in many countries (more than 200 nations are member of FIVB), particularly in African, American, Asian and European nations (www.fivb.org). Volleyball is an intermittent sport that requires performance of frequent high-intensity and short-duration activities interspersed with low-intensity periods (Chamari et al., 2001; Driss et al., 1998; Gabbett and Georgieff, 2007). Successful participation in

\footnotetext{
1 - Institute University of Maia (ISMAI), Castêlo da Maia, Portugal.

2 - Institute Polytechnic of Maia (IPMAIA), Castêlo da Maia, Portugal.

3 - IPMAIA Research Nucleus (N2i), Castêlo da Maia, Portugal.

4 - Research Center in Sports Science, Health and Human Development (CIDESD), Vila Real, Portugal.

5 - Porto Biomechanics Laboratory (LABIOMEP), Porto, Portugal.
} 
this and many other sports requires a high level of technical and tactical skills, which should reflect the influence of training and suitable anthropometric characteristics (Fields et al., 2017; Gaurav et al., 2010). Skills such as the block and spike require a high capacity to perform vertical jumps and are major determinants in volleyball games. Approximately $80 \%$ of game points are obtained when performing these skills (Voigt and Vetter, 2003). Improving them requires regular training (Ciccarone et al., 2007), which should be based on muscular strength and power exercises (Buśko, 2009; Smith et al., 1992). Vertical jump performance is, however, influenced by anthropometric variables that also reflect genetic characteristics (Chatterjee et al., 1999). The available literature shows, for example, that body fat content in female volleyball players generally ranges from 11.7 to $27.1 \%$ (Geladas and Maridaki, 1996; Hassapidou and Mastrantoni, 2001; Papadopoulou et al., 2002; Viviani and Baldin, 1993). As a result, the typical volleyball player somatotype is reported as being mesomorphendomorph (Malousaris et al., 2008). Data comparing morphological characteristics of female volleyball players with players of other sports (Bayios et al., 2006) from different countries (Ayan et al., 2012; Cabral et al., 2008; Duncan et al., 2006; Milic et al., 2012), and for different competition levels and playing positions (Carvajal et al., 2012; Gualdi-Russo and Zaccagni, 2001; Malousaris et al., 2008) are available in the literature.

Although there are some studies involving Portuguese male volleyball players (Marques and Marinho, 2009), there is no data for Portuguese female elite volleyball players comparing anthropometric characteristics with performance data. Therefore, the main goals of this research were to analyze differences in the frequency of each somatotype category between less and more successful female senior volleyball players and to find differences in key performance variables, such as the vertical jump, in relation to the competition level.

It was hypothesized that players from different divisions would exhibit differences in their anthropometric profiles and in the vertical jump height in agreement with observations made in previous studies involving athletes of other nationalities.

\section{Methods}

\section{Participants}

Fifty-nine female volleyball players were analyzed according to their competitive level, forming three independent groups: GA $(n=20$, A1 division, from clubs ranked $1^{\text {st }}$ to $4^{\text {th }}$ in the A1 division), GB ( $\mathrm{n}=21, \mathrm{~A} 1$ division, from clubs ranked $9^{\text {th }}$ to $12^{\text {th }}$ in the $\mathrm{A} 1$ division) and GC ( $\mathrm{n}=$ 18 , competing in the second National League or A2 division). All participants were evaluated during the 2005/06 season. This protocol was approved by the ethics committee of the Sports Sciences, Health and Human Development Research Center (Portugal), and was in accordance with the latest revision of the Declaration of Helsinki.

\section{Anthropometric measures}

The players' body mass, body height and arm span were measured, along with seven skinfolds (triceps, biceps, subscapular, suprailiac, abdominal, thigh and calf), four body perimeters (relaxed brachial, contracted brachial, thigh and calf), and two body diameters (humeral and femoral). After that, the three somatotype classifications (ectomorphy, mesomorphy and endomorphy) were assessed by tracing out the respective somatotype letter (Carter and Heath, 1990).

The body fat percentage was calculated using the Siri equation (Siri, 1961) (Eq. 1)

Percentage of body fat $=(495 /$ Body density $)-450$ (Eq.1)

Body density was calculated using Eq. 2 (Forsyth and Sinning, 1973):

Body density $=1.02415-(0.00169 * \alpha)+\left(0.00444{ }^{*} \beta\right)$ $-(0.0013 * \mu)(E q .2)$

$\alpha$ : subscapular skinfold (mm); $\beta$ : height $(\mathrm{cm}) ; \mu$ : abdominal skinfold (mm)

Fat mass (FM) was estimated using Eq. 3.

Fat mass $=$ Body Weight * (Fat Percentage / 100) (Eq.3)

Lean body mass (LBM) was calculated by subtracting fat mass from body mass.

Jump performance

The height (m) achieved during the block 
and spike was measured using an ergojump device (Globus Ergo tester, Italy). The participants were instructed to perform each test with accuracy. Additionally, key feedback was provided during the tests to ensure a proper jump technique. In the event of a clear error, the test was disregarded, and another attempt was allowed. The vertical jump protocol consisted of three countermovement jumps (block) and three countermovement jumps using arms, with individual technique and coordination (spike). Three-minute rest intervals were given between the two sets of different jumps.

\section{Procedures}

The measurements were conducted in the last third of the competition season (during the play-offs phase) by experienced technicians. To analyze the morphological profiles, anthropometric measurements were collected in accordance with previous literature (Heyward and Stolarczyk, 1996). Height was measured to the nearest $0.1 \mathrm{~mm}$ using a SECA 213 stadiometer. Body mass $(\mathrm{kg})$ was measured to the nearest $50 \mathrm{~g}$ using a SECA 769 digital scale.

The seven skinfolds were assessed using a Harpenden skinfold caliper with a constant pressure of $10 \mathrm{~g} / \mathrm{mm}^{2}$, allowing readings with accuracy of $0.1 \mathrm{~mm}$. Breadths were measured using a small (Campbell 10) and a large (Campbell 20) sliding caliper from Rosscraft Innovations Inc., (Vancouver, Canada), with 0.1 $\mathrm{mm}$ accuracy. The four body perimeters were estimated using an inelastic anthropometric tape with accuracy of $0.1 \mathrm{~cm}$. Each variable was measured three times on the right hemisphere. The mean of all the measurements was considered the final value. All evaluations were performed by the same experienced researcher, assisted by a recorder.

\section{Statistical analysis}

For a comparative analysis of somatotypes between groups, the Somatotype Attitudinal Distance (SAD) interpretative model was used, defined as the spatial distance between two somatopoints, along with the somatotype attitudinal mean (SAM), defined as the average of the SADs of each somatopoint from the mean somatopoint (S) of a sample (Carter and Heath, 1990).

Descriptive statistics and analysis of variance (two-way ANOVA) were used to compare mean values of each measure between A1 (GA and GB) and A2 (GC) competition levels. The Bonferroni post-hoc test was used to assign specific differences in the ANOVA when a significant F-value was computed. The probability of type I error (alpha) was set a priori at 0.05 . All procedures were performed using SPSS 21.0 statistical software (SPSS Inc., Chicago, IL, USA).

\section{Results}

The body composition characteristics are summarized in Table 1. The competition level had a significant effect on body height and arm span $(p<0.05)$, with players from the A1 (GA and GB) and A2 (GC) divisions presenting the highest and the lowest values, respectively. Significant differences were also found in all skinfolds, except for suprailiac. Regarding skinfolds, A1 players (GA and GB) had the lowest values, while A2 players (GC) obtained the highest values. No differences were found in the perimeter variables between groups.

Table 2 shows significant differences in the sum of three, five and seven skinfolds and the percentage of body fat between groups. GA and GB presented the lowest values in the sum of skinfolds, which resulted in a lower body fat content. A2 players presented higher values in the sum of the skinfolds and the percentage of body fat. In relation to lean body mass, GA and GC players had the highest and lowest values, respectively.

The somatoplot (Figure 1) shows the mean values of the players' somatotypes. Generally, all players were characterized as balanced endomorphs. However, A1 players were leaner than A2 players. Both GA and GB groups were identified as endomorph-ectomorphs (4.32.7-3.1 and 4.5-2.3-3.3, respectively). In the A2 division, players (GC) were classified as endomorph-mesomorphs (7.3-3.3-1.9).

The results regarding performance obtained from specific vertical jumps (block and spike) are summarized in Table 3. The mean values of the jumps show that GA players achieved higher results in both jumps, with the only statistically significant difference being between the GA and the GC for the spike jump. 


\section{Table 1}

Anthropometric characteristics of Portuguese female volleyball players from the $A 1$ (GA and GB) and $A 2$ (GC) divisions (Mean $\pm S D$ ).

\begin{tabular}{|c|c|c|c|}
\hline & GA & GB & GC \\
\hline Number of players & 20 & 21 & 18 \\
\hline Body height $(\mathrm{cm})$ & $176.35 \pm 6.12^{a}$ & $174.95 \pm 8.39 \mathrm{~b}$ & $168.17 \pm 7.49 \mathrm{a}, \mathrm{b}$ \\
\hline Body mass (kg) & $68.05 \pm 6.62$ & $64.48 \pm 7.59$ & $66.39 \pm 8.43$ \\
\hline Arm span $(\mathrm{cm})$ & $177.65 \pm 6.09 \mathrm{a}$ & $174.19 \pm 7.07$ & $169.39 \pm 8.49 a$ \\
\hline \multicolumn{4}{|l|}{ Skinfolds (mm) } \\
\hline Triceps & $15.55 \pm 3.97 \mathrm{a}$ & $15.86 \pm 4.16^{\mathrm{b}}$ & $35.89 \pm 6.68 \mathrm{a}, \mathrm{b}$ \\
\hline Biceps & $8.95 \pm 3.25^{a}$ & $9.05 \pm 3.64^{b}$ & $25.44 \pm 4.51^{\mathrm{a}, \mathrm{b}}$ \\
\hline Subscapular & $9.80 \pm 2.17$ a & $9.81 \pm 1.97 \mathrm{~b}$ & $19.17 \pm 6.95^{\mathrm{a}, \mathrm{b}}$ \\
\hline Suprailiac & $19.60 \pm 6.81$ & $21.19 \pm 5.40$ & $23.89 \pm 8.34$ \\
\hline Abdominal & $15.50 \pm 4.52^{\mathrm{a}}$ & $14.95 \pm 5.29 \mathrm{~b}$ & $31.83 \pm 9.54 \mathrm{a}, \mathrm{b}$ \\
\hline Thigh & $22.05 \pm 5.53^{a}$ & $23.57 \pm 5.62^{b}$ & $47.78 \pm 9.12 \mathrm{a}, \mathrm{b}$ \\
\hline Calf & $18.40 \pm 5.34$ a & $20.05 \pm 4.54^{b}$ & $39.00 \pm 7.62 \mathrm{a}, \mathrm{b}$ \\
\hline \multicolumn{4}{|l|}{ Diameters $(\mathrm{cm})$} \\
\hline Humeral & $6.03 \pm 0.38$ & $5.72 \pm 0.35^{b}$ & $6.07 \pm 0.40^{\mathrm{b}}$ \\
\hline Femoral & $9.11 \pm 0.56$ & $8.88 \pm 0.39 b$ & $9.46 \pm 0.68^{b}$ \\
\hline \multicolumn{4}{|l|}{ Perimeters $(\mathrm{cm})$} \\
\hline Brachial relaxed & $26.55 \pm 1.54$ & $25.60 \pm 1.68$ & $26.36 \pm 1.75$ \\
\hline Brachial contracted & $28.03 \pm 2.74$ & $27.67 \pm 1.75$ & $28.28 \pm 2.18$ \\
\hline Thigh & $51.70 \pm 4.51$ & $50.57 \pm 3.45$ & $53.28 \pm 4.86$ \\
\hline Calf & $37.21 \pm 2.35$ & $36.31 \pm 2.30$ & $37.03 \pm 2.87$ \\
\hline \multicolumn{4}{|c|}{ a significant difference $(p<0.05)$ between $G A$ and GC divisions ( $A 1$ first and A2) } \\
\hline
\end{tabular}


Table 2

Body composition indices and somatotype variables of Portuguese female volleyball players from the $A 1$ (GA and GB) and $A 2$ (GC) competition levels (Mean $\pm S D$ ).

\begin{tabular}{|c|c|c|c|}
\hline & GA & GB & GC \\
\hline Sum of 7SKFS (mm) & $111.29 \pm 21.77^{a}$ & $113.06 \pm 23.59^{b}$ & $198.61 \pm 38.66^{a, b}$ \\
\hline Sum of 5SKFS (mm) & $86.57 \pm 16.51 \mathrm{a}$ & $89.29 \pm 16.57 b$ & $148.27 \pm 28.89 a, b$ \\
\hline Sum of 3SKFS (mm) & $45.21 \pm 11.38^{a}$ & $47.36 \pm 10.07^{b}$ & $71.52 \pm 20.18^{a, b}$ \\
\hline Body fat (\%) & $21.30 \pm 2.61^{a}$ & $21.80 \pm 2.32^{b}$ & $27.29 \pm 2.71^{\mathrm{a}, \mathrm{b}}$ \\
\hline Fat mass (kg) & $14.54 \pm 2.67 \mathrm{a}$ & $14.11 \pm 2.63^{b}$ & $18.13 \pm 2.93^{a, b}$ \\
\hline Fat free mass $(\mathrm{kg})$ & $53.51 \pm 4.94{ }^{a}$ & $50.36 \pm 5.57$ & $48.26 \pm 6.40^{a}$ \\
\hline Endomorphy & $4.26 \pm 0.88^{a}$ & $4.51 \pm 0.91$ & $7.28 \pm 1.62^{a, b}$ \\
\hline Mesomorphy & $2.71 \pm 1.00$ & $2.25 \pm 0.92^{b}$ & $3.33 \pm 1.24^{b}$ \\
\hline Ectomorphy & $3.08 \pm 0.88^{a}$ & $3.29 \pm 1.06^{b}$ & $1.90 \pm 1.31^{\mathrm{a}, \mathrm{b}}$ \\
\hline Somatotype Category & endomorph-ectomorphs & endomorph-ectomorphs & endomorph-mesomorphs \\
\hline
\end{tabular}

a significant difference $(p<0.05)$ between GA and GC divisions ( $A 1$ first and $A 2)$

${ }^{b}$ significant difference $(p<0.05)$ between GB and GC divisions (A1 last and A2)

Table 3

Technical vertical jump performances of Portuguese female volleyball players from the A1 (GA and GB) and A2 (GC) competition level (Mean $\pm S D$ ).

\begin{tabular}{|c|c|c|c|}
\hline & GA & GB & GC \\
\hline $\mathrm{N}$ & 20 & 21 & 18 \\
\hline Blocking height (m) & $0.36 \pm 0.06$ & $0.35 \pm 0.06$ & $0.33 \pm 0.05$ \\
\hline Spiking height (m) & $0.43 \pm 0.05^{\mathrm{a}}$ & $0.42 \pm 0.06$ & $0.37 \pm 0.05^{\mathrm{a}}$ \\
\hline
\end{tabular}




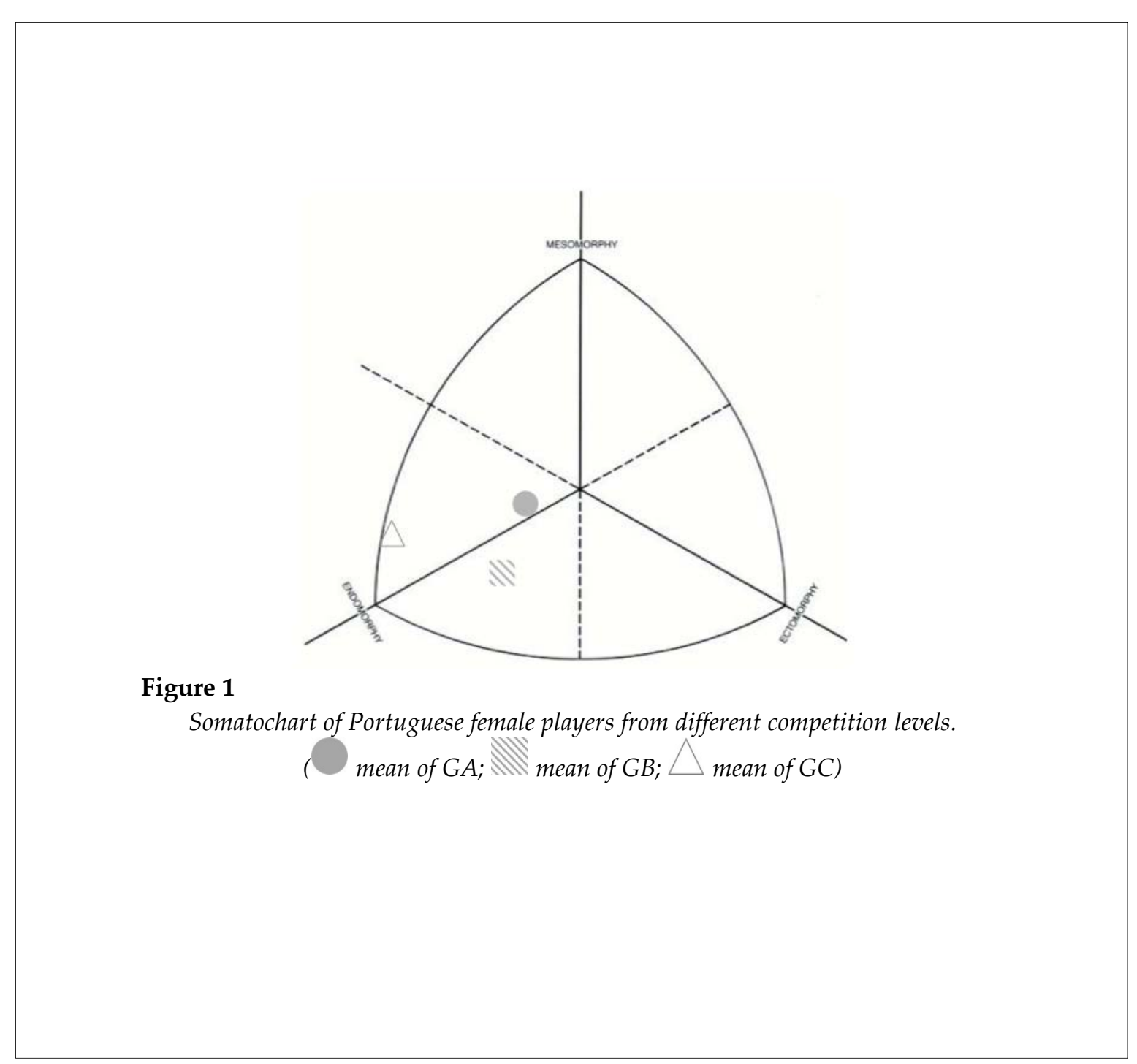

\section{Discussion}

The results of this study show that Portuguese female volleyball players competing in the first and second divisions present different body composition and somatometric values.

Body height and vertical jump height values appear to be key factors in determining volleyball performance. As expected, differences were found in body height values between the two divisions (GA, A1 players $176.4 \pm 6.12 \mathrm{~cm}$ and A2 players $168.17 \pm 7.49 \mathrm{~cm}$ ). Similar results were found in Greek international elite players (177.1 \pm $6.5 \mathrm{~cm}$ ) (Malousaris et al., 2008). However, volleyball players can be even taller, for example, Chinese female players $(183.6 \pm 5.8 \mathrm{~cm})$ in the top eight teams of the 2007-2008 national championship. These differences in body height seem to be a determining factor for success in elite volleyball performance. For example, from 1992 to 2002, the number of female volleyball players taller than $190 \mathrm{~cm}$ increased rapidly (Gao, 2006). This trend confirms the importance that coaches attribute to this variable when selecting the most talented players. These changes in anthropometric profiles can be confirmed in the height indices of the top six female volleyball teams: the mean increased by $0.03 \mathrm{~cm}$ from 1.81 to $1.84 \mathrm{~m}$ between the 26th to the 29th Olympic Games (Gao, 2006; Zhang, 1998). Moreover, body height and the arm span, which also display significant differences between the GA and GC groups, appear to have a high level of heritability (Chatterjee et al., 1999), which supports their use for talent detection.

Body fat and fat free mass are also two important variables for elite volleyball players. In 
fact, these variables are strongly correlated with the ability to increase muscular strength, which contributes to better performance. Differences were found between the groups, with A1 players showing less fat mass and greater fat free mass. The mean of the sum of 3, 5 and 7 skinfolds of the A1 division players presented lower values of fat mass and higher values of fat free mass compared with A2 division players.

The body fat percentages for A1 players (GA: $21.3 \pm 2.61 \%$ and GB: $21.80 \pm 2.32 \%$ ) were similar to the values reported by Papadopoulou et al. (2002) in a study with Greek female volleyball players from the national team $(22.4 \pm 4.7 \%)$ and the A1 $(21.3 \pm 5.5 \%)$ division. Another study by Malousaris et al. (2008), also with female volleyball players in the A1 Greek National League, presented similar results $(22.7 \pm 2.9 \%)$. However, in general, the A2 Portuguese female players had higher body fat percentages compared to other volleyball players of different ages and competition levels (Geladas and Maridaki, 1996; Hassapidou and Mastrantoni, 2001; Papadopoulou et al., 2002).

The negative correlation between the body fat percentage and performance is well documented (Nikolaidis, 2013). In fact, Table 2 confirms the above-mentioned trend, with GA and GB players presenting lower values than GC players, while also exhibiting higher vertical jump heights, especially for spike actions.

Regarding the somatotype, significant differences were found between A1 and A2 players in the endomorphy and ectomorphy components, with A1 players presenting lower values in endomorphy and higher values of ectomorphy, as expected. The somatoplot (Figure 1) shows that, in general, all players were characterized as balanced endomorphs. Yet A1 players were leaner than A2 players. Both groups (GA and GB) from the A1 division were identified as endomorph-ectomorphs (4.3-2.7-3.1 and 4.5-2.33.3, respectively), while players from the A2 division (GC) were characterized as endomorphmesomorphs (7.3-3.3-1.9). Nevertheless, the first component (endomorph) of A2 division players presented higher values than A1 players. Compared to the A2, the morphology of A1 players was characterized by higher ectomorphy and lower endomorphy. These results are similar to those found by Malousaris et al. (2008) in a study with Greek female players that were characterized as endomorph-ectomorphs (3.2-2.43.2) and balanced endomorphs (3.6-2.9-2.7) in the $\mathrm{A} 1$ and $\mathrm{A} 2$ divisions, respectively. Also, in a study with Italian A1 and A2 volleyball leagues (GualdiRusso and Zaccagni, 2001), differences were observed between the two somatotypes (2.9-3.13.0 and 3.1-3.5-2.7), with A1 players having lower endomorphy and higher ectomorphy than A2 players, whereas the mesomorphy was the main component. This trend was also confirmed in a study involving elite Chinese female volleyball players (3.7-2.9-4.0), whose main component was ectomorphy.

With respect to morphological characteristics, these profiles reflect the genetic make-up of the athletes, but also the level of training, probably one of the main reasons for the differences found between $\mathrm{A} 1$ and A2 players. A2 players had high values of endomorphy, which reflects the lack of elite training and lower performance quality in this division. The results of the $\mathrm{A} 1$ division are closer to the values found in studies with other international elite players but are still at a lower level. Together with physical profiles, these morphological variables seem to be key elements for coaches when selecting and detecting talents who may reach elite levels in volleyball.

\section{Conclusion}

The results of this study suggest that A1 players have a better morphological profile for high performance volleyball, since they had lower fat content and higher lean body mass. Regarding somatotype values, A1 players displayed the lowest endomorphy values and the highest ectomorphy values in comparison with A2 players. Players in the A1 division had morphological profiles and body composition values that are more suitable for high performance volleyball (i.e. lower fat percentage and higher values in body height and mass). This agrees with the volleyball ideal values for elite performance, suggesting a strong correlation with muscular strength and linearity.

Better performance among A1 players was also confirmed in spike height, suggesting that anthropometric and body composition indices as well as the somatotype could play an important role in specific volleyball performancerelated skills. Since some anthropometric 
variables are more likely to express the influence of heritability, future studies should analyze their relative contribution, along with environmental components, such as those introduced by nutritional aids or training.

\section{References}

Ayan V, Bektas Y, Ali Emre E. Anthropometric and performance characteristics of Turkey National U-14 volleyball players. Afr. J. Phys. Health Educ. Recreat. Dance, 2012; 18(2): 395-403

Bayios IA, Bergeles NK, Apostolidis NG, Noutsos KS, Koskolou MB. Anthropometric, body composition and somatotype differences of Greek elite female basketball, volleyball and handball players. J Sport Med Phys Fit, 2006; 46(2): 271-280

Buśko K. Changes of power-velocity relationship in volleyball players during an annual training cycle. Human Movement, 2009; 10(2): 149-152

Cabral BG, Cabral SA, Batista GR, Fernandes FJ, Knackfuss MI. Somatotype and anthropometry in brazilian national volleyball teams. Motricidade, 2008; 4(1): 67-73

Carvajal W, Betancourt H, León S, Deturnel Y, Martínez M, Echevarría I, Castillo ME, Serviat N. Kinanthropometric profile of Cuban women Olympic volleyball champions. MEDICC Rev, 2012; 14(2): 16-22

Carter JEL, Heath BH. Somatotyping: Development and applications (Cambridge Studies in Biological and Evolutionary Anthropology), Cambridge University, Cambridge; 1990

Chamari K, Ahmaidi S, Blum JY, Hue O, Temfemo A, Hertogh C, Mercier B, Préfaut C, Mercier J. Venous blood lactate increase after vertical jumping in volleyball athletes. Eur J Appl Physiol, 2001; 85(1-2): 191194

Chatterjee S, Das N, Chatterjee P. The estimation of the heritability of anthropometric measurements. Applied Human Science, 1999; 18(1): 1-7

Ciccarone G, Croisier JL, Fontani G, Martelli G, Albert A, Zhang L, Cloes M. Comparison between player specialization, anthropometric characteristics and jumping ability in top-level volleybal players. Med Sport, 2007; 61: 29-43

Driss T, Vandewalle H, Monod H. Maximal power and force-velocity relationships during cycling and cranking exercises in volleyball players. Correlation with the vertical jump test. J. Sport Med Phys Fit, 1998; 38(4): 286-293

Duncan MJ, Woodfield L, Al-Nakeeb Y. Anthropometric and physiological characteristics of junior elite volleyball players. Brit J Sport Med, 2006; 40(7): 649-651

Fields JB, Metoyer CJ, Casey JC, Esco MR, Jagim AR, Jones MT. Comparison of body composition variables across a large sample of NCAA women athletes from six competitive sports. J Strength Cond Res, 2017; Nov 16

Forsyth HL, Sinning WE. The anthropometric estimation of body density and lean body weight of male athletes. Med Sci Sports, 1973; 5(3): 174-180

Gabbett T, Georgieff B. Physiological and anthropometric characteristics of Australian junior national, state, and novice volleyball players. J. Strength Cond Res, 2007; 21(3): 902-908

Gao SL. Comparative analysis on the physique and height over net of women's volleyball players between the 27th and the 28th Olympic Games. Journal of Beijing Sport University, 2006; 29: 700-702

Gaurav V, Singh M, Singh S. Anthropometric characteristics, somatotyping and body composition of volleyball and basketball players. J Phys Educ Sport Manag, 2010; 1(3): 28-32

Geladas N, Maridaki M. Kinanthropometric profile of Greek female volleyball players. Kinesiology, 1996; 1: 46-55

Gualdi-Russo E, Zaccagni L. Somatotype, role and performance in elite volleyball players. J Sports Med Phys Fit, 2001; 41(2): 256-262

Hassapidou MN, Mastrantoni A. Dietary intakes of elite female athletes in Greece. J Hum Nutr Diet, 2001; 14: 391-396 
Heyward VH, Stolarczyk LM. Applied body composition assessment. Champaign, IL: Human Kinetics Europe; 1996

Malousaris GG, Bergeles NK, Barzouka KG, Bayios IA, Nassis GP, Koskolou MD. Somatotype, size and body composition of competitive female volleyball players. J Sci Med Sport, 2008; 11: 337-344

Marques M, Marinho D. Physical parameters and performance values in starters and non-starters volleyball players: A brief research note. Motricidade, 2009; 5(3): 7-11

Milic M, Grgantov Z, Katic R. Somatotype of young female volleyball players. Exercise and Quality of Life, 2012; 4(2): 7-14

Nikolaidis PT. Body mass index and body fat percentage are associated with decreased physical fitness in adolescent and adult female volleyball players. J Res Med Sci, 2013; 18(1): 22-26

Papadopoulou SD, Papadopoulou SK, Gallos GK, Likesas G, Paraskevas G, Fachantidou A. Anthropometric differences of top Greek and foreign volleyball players. Int J Volleyball Res, 2002; 5: 26-29

Papadopoulou SD, Gallos GK, Paraskevas G, Tsapakidou A, Fachantidou A. The somatotype of Greek female volleyball athletes. Int J Volleyball Res, 2002; 5(1): 22-25

Siri WE. Body composition from fluid spaces and density. Analysis of methods. Techniques for measuring body composition. Washington, DC: Brozek J, Henschel A. (Eds.) National Academy of Sciences, 223-244; 1961

Smith DJ, Roberts D, Watson B. Physical, physiological and performance differences between Canadian national team and university volleyball players. J Sports Sci, 1992; 10(2): 131-138

Viviani F, Baldin F. The somatotype of "amateur" Italian female volleyball players. J Sports Med Phys Fit, 1993; 33: 400-404

Voigt HF, Vetter K. The value of strength-diagnostic for the structure of jump training in volleyball. Eur J Sport Sci, 2003; 3(3): 1-10

Zhang R. Features of the women volleyball player's body shape and bounce quality in the 26th Olympic game-analyzing the present situation of Asian women volleyball teams. Journal of Guangzhou Physical Education Institute, 1998; 18: 99-103

\title{
Corresponding author:
}

\author{
Alberto Carvalho \\ Institute University of Maia (ISMAI), Castêlo da Maia, Portugal. \\ Address: ISMAI - Instituto Superior da Maia. Av. Carlos Oliveira Campos \\ Castelo da Maia. 4475-690 Avioso S. Pedro \\ Phone number: +351 229825319 \\ Fax number: +351 229825331 \\ Email: acarvalho@ismai.pt
}

